Original Research Paper

\title{
Comparison of Analytical and Numerical Results for the Charring Rate of the Timber-Concrete Beam
}

\author{
${ }^{1}$ Zuzana Kamenická, ${ }^{1}$ Jaroslav Sandanus, ${ }^{2}$ Lukáš Blesák, ${ }^{2}$ Kamila Cábová and ${ }^{2}$ František Wald \\ ${ }^{1}$ Department of Steel and Timber Structures, Faculty of Civil Engineering, \\ Slovak University of Technology in Bratislava, Bratislava, Slovak Republic \\ ${ }^{2}$ Department of Steel and Timber Structures, Faculty of Civil Engineering, \\ Czech Technical University in Prague, Prague, Czech Republic
}

\author{
Article history \\ Received: 27-04-2018 \\ Revised: 25-05-2018 \\ Accepted: 01-6-2018 \\ Corresponding Author: \\ Kamenická Z \\ Department of Steel and \\ Timber Structures, Faculty of \\ Civil Engineering, \\ Slovak University of \\ Technology in Bratislava, \\ Bratislava, Slovak Republic \\ Email: zuzana.kamenicka@stuba.sk
}

\begin{abstract}
Modelling the thermal response of timber is a primary issue for the assessment of the mechanical resistance of timber structures exposed to fire. Therefore, this paper analyses various advanced calculation methods of determining the charring rate. Authors of this contribution use analytical calculation methods according to two different publications and also a numerical calculation by means of program based on Finite Element Method (FEM). Input values of parameters in these calculations were derived from an experiment on a timber-concrete beam, which was realised by two authors of this paper in the past. In conclusion, the values of onedimensional charring rate of timber calculated by different methods are compared. It is necessary to pay attention to the fact that the resultant values can significantly differ depending on various input values in the analytical calculations. The charring rate increases until a certain time at the beginning of the charring and then it starts to slightly decrease. However, not all of the calculation methods presented in this paper correspond with that.
\end{abstract}

Keyword: Fire, Timber, Advanced Modelling, Charring Rate

\section{Introduction}

In the structural fire design of timber structures, it is crucial to correctly identify the residual cross-section, i.e. the cross-section capable of carrying the load after a period of fire exposure. In its determination, the charring depth is a relevant factor (Werther, 2016) and this, in turn, is related to the charring rate. The standard (STN EN 1995-1-2, 2008) contains two calculation methods simplified and advanced. The reduced cross-section method includes a zero-strength layer as an additional layer to the charring depth. A few years ago, concerns have been raised regarding the zero-strength layer being non-conservative in some cases. It is recommended to revise reduced cross-section method and provide it with solid experimental basis and advanced calculations (Schmid et al., 2014). It can be complicated to determine the zero-strength layer, as it differs in various sources (Klippel, 2014; Erchinger, 2009; König, 2005; Cachim and Franssen, 2010) etc. In the simplified methods, a constant value for the charring rate is assumed (STN EN 1995-1-2, 2008). Principles of the design of separating and load-bearing timber structures and their connections by means of simplified methods are described in detail in (Frangi, 2010). Furthermore, the guideline also describes thermal properties of timber and insulation materials. The advanced methods can be used for various cases which are not included in the standard. A FEM-based software is used for the advanced calculation methods, where the thermal properties are specified depending on the temperature. The publication (Erchinger, 2009) reports on multiple-shear steel-timber connections and describes the thermal properties of timber, steel and air according to various authors. These properties depend on a variety of parameters, for example density (Kollmann, 1951) and moisture content (Hietaniemi and Mikkola, 2010; Klippel, 2014)). In real conditions, the charring rate gradually decelerates, mainly due to the formation of char layer and pyrolysis, both of which act as a thermal insulation. These factors are considered through the change of thermal properties in higher temperatures. In addition to the numerical calculations, there are various analytical calculation methods which are described in works such as (Mikkola, 1991) or (Hietaniemi, 2005). These publications also deal with the determination of the charring rate with consideration of various factors (various emissivity, density, moisture, heat flux, etc.). The results obtained from the calculations according to the above-mentioned publications vary considerably. Alternatively, experiments can be conducted to obtain 
the most accurate data. It is possible to determine the charring rate based on the charring depth for models in FEM-based software or for experiments. The char-line is defined as the position of isotherm of a specific temperature and its values fluctuate between 200 and $350^{\circ} \mathrm{C}$ according to various publications (Beilicke, 2009). In the majority of cases, the 300-degree isotherm is considered, which is also in accordance with the standard (STN EN 1995-1-2, 2008). Based on this assumption, it is possible to determine the charring rate with the following equation:

$$
\beta=d_{\text {char }} / t
$$

Where:

$\beta=$ The charring rate $(\mathrm{mm} / \mathrm{min})$

$d_{\text {char }}=$ The charring depth $(\mathrm{mm})$

$\mathrm{t} \quad=$ The time of fire exposure (min)

This paper presents an experiment performed on a timber-concrete beam (realised by Caldová et al. (2014) and described in the next chapter), a numerical model of this beam and analytical models for determining the charring rate according to (Mikkola, 1991) and (Hietaniemi, 2005). In conclusion, these methods are mutually compared and the results are analysed to provide valid conclusions.

\section{Experiment}

The experiment on a timber-concrete beam was conducted in the testing premises of PAVUS a.s. in cooperation with the Czech Technical University in Prague, the Czech Academy of Sciences and Designtec ltd. (Caldová et al., 2014). The beam was made of timber with strength class GL24 h and a steel fibre reinforced concrete of the concrete class $\mathrm{C} 45 / 55$. The density of the timber was determined at the value of $512 \mathrm{~kg} / \mathrm{m}^{3}$. The moisture was measured in six locations in the beam with a resistive moisture meter in accordance with (STN EN 13183-1, 2003) and it was determined at the value of $12 \%$. The total length of the beam was $4.7 \mathrm{~m}$. The temperature inside the furnace was controlled by plate thermocouples. The aim was to follow the standard temperature curve ISO 834 (STN EN 1991-1-2, 2007). Type K thermocouples (according to STN EN 1363-1, 2013) were used inside of the tested beam. These wired thermocouples were drilled in from the side of the beam. The position of the thermocouples in transverse direction is illustrated in the Fig. 1 (with numbers 23, 24, 43, 44, 45). The composite beam was exposed to standard fire according to ISO 834 on three sides and was subjected to a four-point bending test (Caldová et al., 2014). It was loaded continuously until the failure force of $34 \mathrm{kN}$ was reached. This force was applied to the beam for $20 \mathrm{~min}$ before the start of the fire test to ensure the stabilization of the load and deflection. The mid-span deflection of the beam reached $12.2 \mathrm{~mm}$ under the maximum force induced by the hydraulic cylinders, i.e. $2 \times 17 \mathrm{kN}$. With this value of deflection, a shear crack appeared in the timber beam, accompanied by a sudden drop in the load force (Caldová et al., 2014). The experiment was terminated in the $22 \mathrm{nd}$ min of the standard fire due to the failure of the beam.

In order to determine the charring depth, it was first necessary to correctly identify the position of the 300degree isotherm. Fig. 2a (left) shows the distribution of temperatures according to the publication (Erchinger, 2009), where temperatures were analysed in a cross-section with the dimensions $200 \times 200 \mathrm{~mm}$ in 10th, 30th, 60th and 90 th min. Figure $2 \mathrm{~b}$ (right) shows the estimated distribution of temperatures in the 10th, 15th, $20^{\text {th }}$ and $22 \mathrm{nd} \mathrm{min}$.

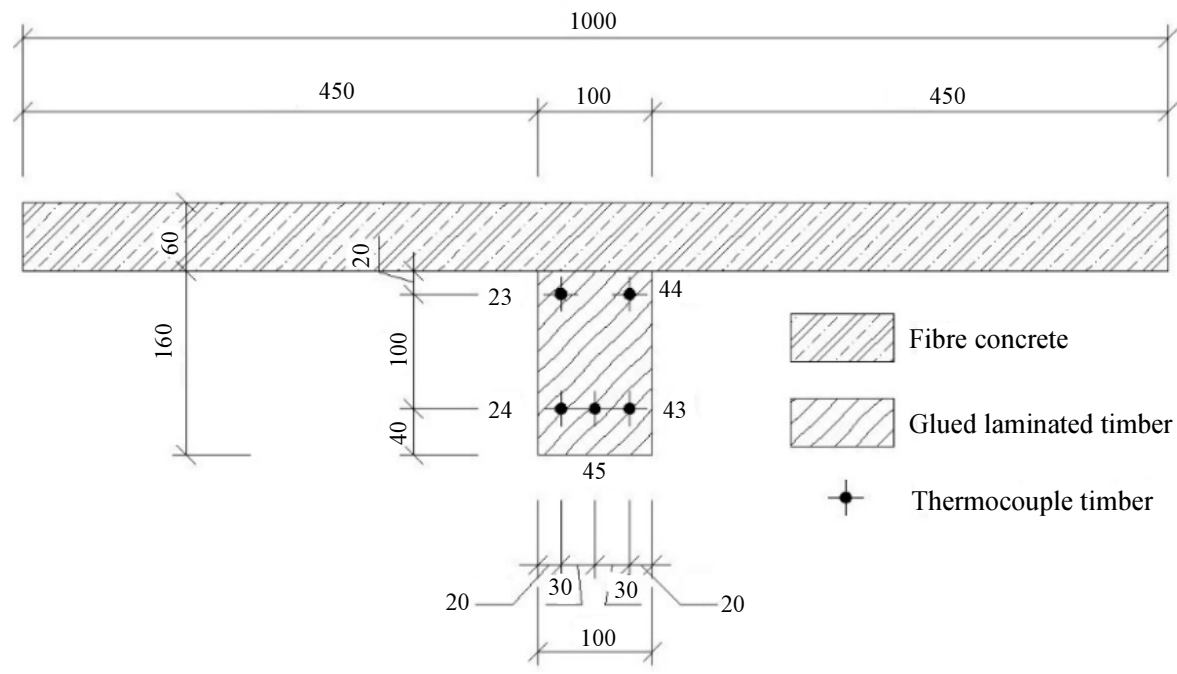

Fig. 1: The position of the thermocouples in the cross-section of the tested timber-concrete beam (distances are in mm) 

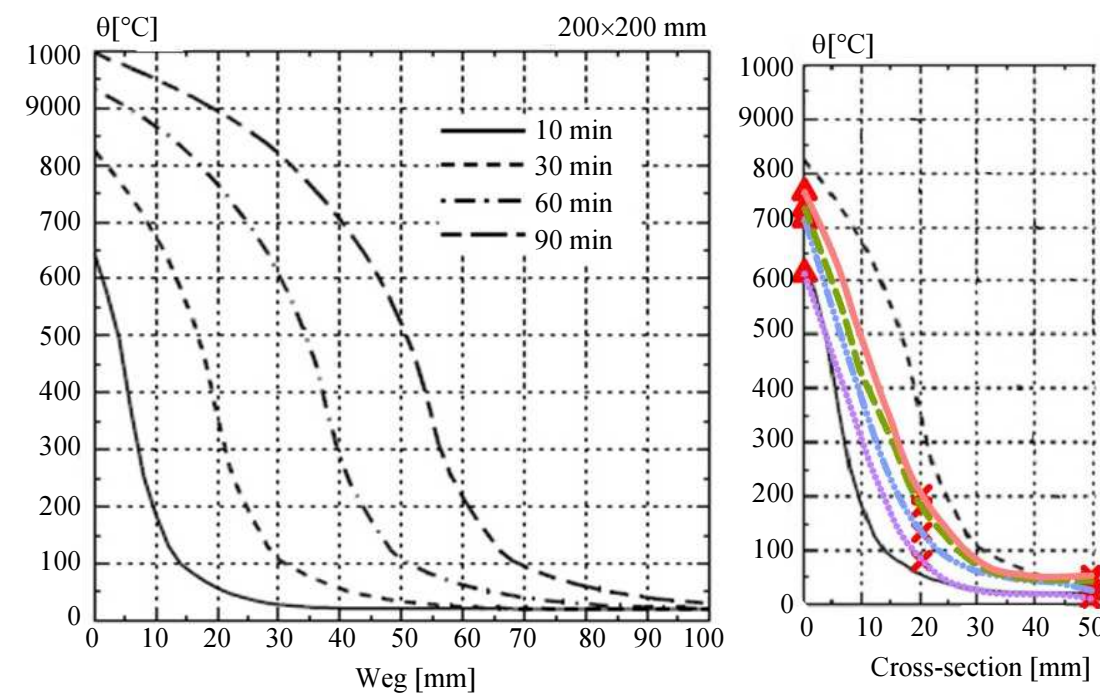

$\times$ Measured temperature

A Estimated temperature

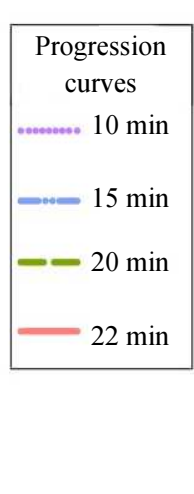

Fig. 2: The distribution of temperatures according to the publication (Erchinger, 2009) (left) and the estimation of temperatures in the cross-section of the timber-concrete beam with the comparison according to (Erchinger, 2009) (right)

The specified temperatures at the depth of 20 and $50 \mathrm{~mm}$ were measured during the experiment and temperatures at the surface of the timber member were estimated according to the actual distribution of temperatures in the oven. Data from these three points (at the surface, at the depth of 20 and $50 \mathrm{~mm}$ ) was used as the basis for estimating the distribution of temperatures. Polynomial trend lines (curved lines used for fluctuated data) were created by Microsoft Excel for capturing the distribution, consisting of R-square values from 0.9994 to 1 . The position of the 300-degree isotherm in the cross-section was successively determined by means of the equations defined by these curves. Afterwards, the charring depth and subsequently the charring rate, were calculated according to the equation (1) from the introduction.

\section{Used Properties of Timber}

The thermal properties of timber used for the numerical simulation and analytical calculations are summarised in the Table 1 .

\section{Modelling of the Timber-Concrete Beam in FE- program}

For the purpose of this study, the software Ansys Workbench was used. The numerical model was created based on the above-mentioned experiment on the timberconcrete composite beam. The elements types used were PLANE77, CONTA172, TARGE169 and SURF151. The element PLANE77 is an eight-node element with one degree of freedom (temperature at each node). The element CONTA172 represents a deformable surface in contact with a 2-D "target" surface (TARGE169) with the possibility of sliding. This element is located on the surface of 2-D solid elements (PLANE77). The target segment element TARGE169 is used to represent 2-D "target" surfaces for the associated contact elements
(CONTA172). The target surface is discretized by a set of target segment elements. The two- to four-node element SURF151 may be used for various types of load (including thermal load) and surface effect applications (Thermal Analysis Guide, 2009). The element size was 5 $\mathrm{mm}$ for the concrete part and $2.5 \mathrm{~mm}$ for the timber part. Symmetric behaviour was defined in the contact region between the materials. Thermal load was applied through convection and radiation. Film coefficient (convection coefficient) was $25 \mathrm{~W} /\left(\mathrm{m}^{2} \mathrm{~K}\right)$. Emissivity was 0.8 for timber and 0.7 for concrete (according to STN EN 19951-2, 2008 a STN EN 1992-1-2, 2007). The time step settings of the transient thermal analysis were defined as follows: $0.6 \mathrm{~s}$ initial time step, $0.006 \mathrm{~s}$ minimal time step and $6 \mathrm{~s}$ maximal time step. The thermal properties of the timber were adopted from (STN EN 1995-1-2, 2008) and those of concrete from (STN EN 1992-1-2, 2007). The densities and moistures were specified according to (Caldová et al., 2014). The thermal conductivity was consistent with the values given by the standard, whilst the specific heat capacity was modified (stated in Table 1). The optimization process (the modification of the specific heat capacity) was to be stopped once the deviation of less than $20^{\circ} \mathrm{C}$ (less than $15 \%$ ) was reached. The temperatures in the 20th minute were compared in specified points where the thermocouples were placed in the experiment. The temperatures from the experiment and from the simulation are shown in the Fig. 3. Values from the experiment could be influenced by many factors (distance between the thermocouple and timber, etc.) and, moreover, only one test as performed. The difference between the results could be the result of one or several of the mentioned factors. The position of the 300-degree isotherm in the cross-section was determined by means of the above described program. Afterwards, the charring depth and subsequently the charring rate, were determined according to Equation (1). 
Table 1: Thermal properties of timber used in the analyses

\begin{tabular}{llcc}
$\begin{array}{l}\text { Temperature } \\
\left({ }^{\circ} \mathrm{C}\right)\end{array}$ & $\begin{array}{l}\text { Thermal conductivity } \\
(\mathrm{W} /(\mathrm{m} . \mathrm{K}))\end{array}$ & $\begin{array}{l}\text { Specific heat capacity } \\
(\mathrm{J} /(\mathrm{kg} . \mathrm{K}))\end{array}$ & $\begin{array}{l}\text { Density } \\
\left(\mathrm{kg} / \mathrm{m}^{3}\right)\end{array}$ \\
\hline 20 & 0.12 & 1070 & 512.0 \\
98.9 & - & 1237.8 & 512.0 \\
99 & - & 9511.1 & 512.0 \\
120 & - & 9441.2 & 457.1 \\
120.1 & - & 1482.6 & 457.1 \\
200 & 0.15 & 1398.7 & 457.1 \\
250 & - & 1132.9 & 425.1 \\
300 & - & 496.5 & 347.4 \\
350 & 0.07 & 594.4 & 237.7 \\
400 & - & 699.3 & 173.7 \\
500 & 0.09 & - & - \\
600 & - & 979.1 & 128.0 \\
800 & 0.35 & 1153.9 & 118.9 \\
1200 & 1.5 & 1153.9 & 0.1 \\
\hline
\end{tabular}

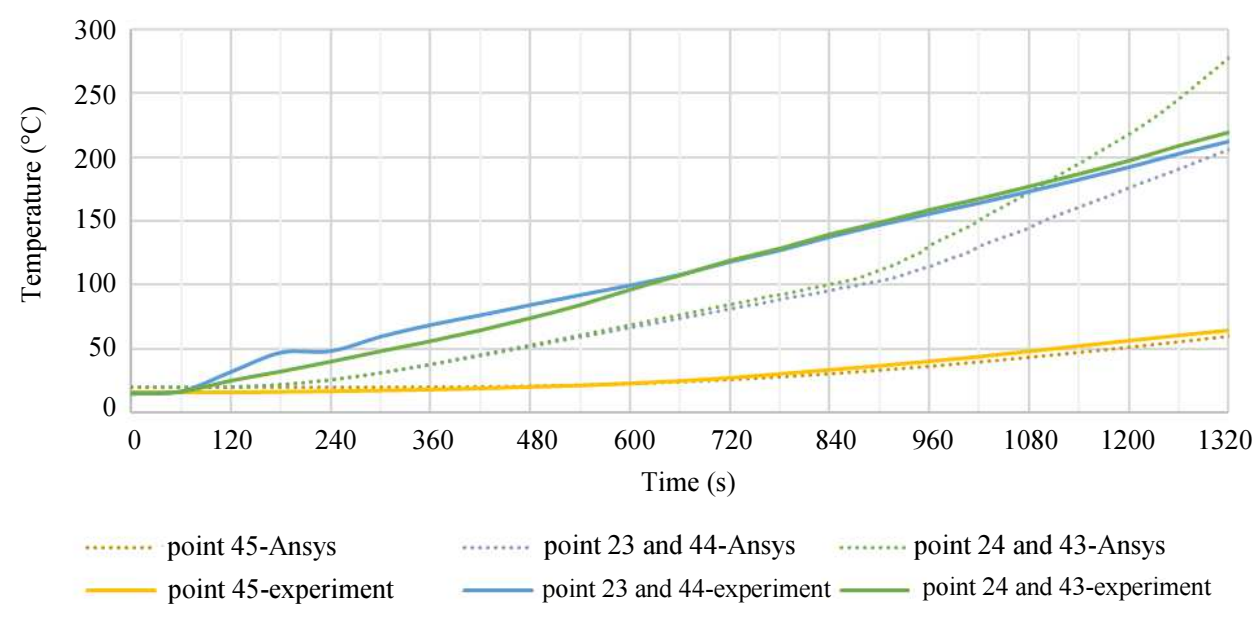

Fig. 3: The comparison of the temperatures measured during the experiment in 23, 44, 24, 43 and 45 with temperatures from FEMbased program

\section{Analytical Models}

\section{Charring Rate Calculation According to (Mikkola, 1991)}

The publications (Mikkola, 1991) and (Mikkola, 1990) state that more than 50 experiments were conducted to establish the influence of the moisture and density on the charring rate of timber. The equations and boundary conditions for the calculation of the charring rate were derived from the results.

The charring rate is calculated according to (Mikkola, 1991) as:

$$
\beta=\frac{\mathrm{q}_{\mathrm{e}}-\mathrm{q}_{\mathrm{L}}}{\rho \cdot\left(\mathrm{c}_{0} \cdot\left(T_{p}-T_{0}\right)+L_{v}+\left(\left(c_{w}-c_{0.1}\right) \cdot\left(T_{v}-T_{0}\right)+L_{v, w}\right) \cdot w\right)}
$$

Where:

$q_{e}=$ The net heat flux to unit surface (it is referred to as $h_{\text {net }}$ according to (STN EN 1991-1-2, 2007)) and it is composed of the radiation and the convection component $\left(\mathrm{W} / \mathrm{m}^{2}\right)$
$q_{L}=$ The heat losses on the char surface $\left(\mathrm{W} / \mathrm{m}^{2}\right)$

$\rho=$ The wood density (used value $512 \mathrm{~kg} / \mathrm{m}^{3}$ )

$c_{O}=$ The specific heat capacity of wood for temperature between $T_{0}$ and $T_{p}(\mathrm{~J} /(\mathrm{kg} . \mathrm{K}))$

$c_{w}=$ The specific heat capacity of water vaporisation (J/(kg.K))

$c_{O .1}=$ The specific heat capacity expressed as the average of specific heat capacities for the temperature of $20^{\circ} \mathrm{C}$ and $99^{\circ} \mathrm{C}(\mathrm{J} /(\mathrm{kg} . \mathrm{K}))$

$T_{p}=$ The average pyrolysis layer temperature (used value $360^{\circ} \mathrm{C}$ )

$T_{0}=$ The initial temperature (used value $20^{\circ} \mathrm{C}$ )

$T_{v}=$ The temperature of water vaporisation (used value $100^{\circ} \mathrm{C}$ )

$L_{v}=$ The heat of vaporisation of dry wood (used value $2250 \mathrm{~J} / \mathrm{kg}$ )

$L_{v, w}=$ The heat of vaporisation of water (used value $2260 \mathrm{~J} / \mathrm{kg}$ )

$w=$ The wood moisture content (used value 12\%) 
The used input parameters in this analysis are stated in brackets and are also summarised in the Table 1.

The following parameters vary according to different authors (who are mentioned in publication (Hietaniemi, 2005)) or conditions and the influence of variation of these parameters is illustrated in the Fig. 4 to 9 . These figures serve to illustrate the differences in the results of charring rate with different values of individual parameters, where $100 \%$ represents the highest value of the charring rate compared to other values which are affected by changes in the values of the examined parameters:

1. The heat of vaporisation of dry wood $\mathrm{L}_{\mathrm{v}}$ (Fig. 4)
a. $2250 \mathrm{~kJ} / \mathrm{kg}$ (Mikkola, 1989)
b. $300 \mathrm{~kJ} / \mathrm{kg}$ (de Souza Costa and Sandberg, 2004)
c. $125 \sim 210 \mathrm{~kJ} / \mathrm{kg}$ "before the break point" (Tinney, 1965)
d. $840 \sim 2300 \mathrm{~kJ} / \mathrm{kg}$ "after the break point" (Tinney, 1965)

2. The temperature of the wood surface $\theta_{m}$ (Fig. 5)
a. $\quad 600 \sim 800^{\circ} \mathrm{C}$ (Mikkola, 1991)

3. The heat transfer coefficient on the surface $\alpha_{c}$ (Fig. 6)
a. $25 \mathrm{~W} /\left(\mathrm{m}^{2} . \mathrm{K}\right)(\mathrm{STN}$ EN 1991-1-2, 2007)
b. $11 \sim 15$ and $20 \sim 35 \mathrm{~W} /\left(\mathrm{m}^{2} . \mathrm{K}\right.$ ) (Hietaniemi, 2005)

4. The surface emissivity of the member $\varepsilon_{\mathrm{m}}$ (Fig. 7)
a. $\quad 0.8$ (STN EN 1991-1-2, 2007)
b. 0.75 (Hietaniemi, 2005)
c. 0.7 (Mikkola, 1991)
d. $\quad 0.7 \sim 1$ (Erchinger, 2009)

5. The density of dry wood $\rho_{0}$ (Fig. 8)
a. $120 \mathrm{~kg} / \mathrm{m}^{3}$ (Mikkola, 1990)
b. $\quad 260 \sim 410 \mathrm{~kg} / \mathrm{m}^{3}$ (STN EN 1995-1-2, 2008)
c. $\quad 280 \sim 650 \mathrm{~kg} / \mathrm{m}^{3}$ (Hietaniemi, 2005)

6. The wood moisture content w (Fig. 8)

a. $0 ; 8 ; 10 ; 12 \%$ (Hietaniemi and Mikkola, 2010)

7. The time of fire exposure $t$ (Fig. 9)
a. $\quad 0 \sim 120 \mathrm{~min}$

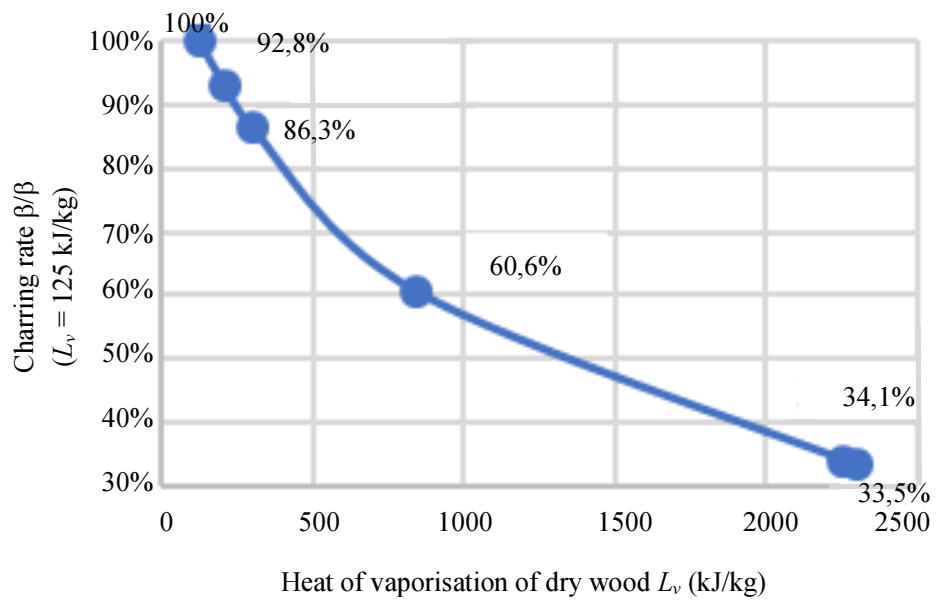

Fig. 4: The influence of the variable value of the heat of vaporisation of dry wood Lv on the charring rate

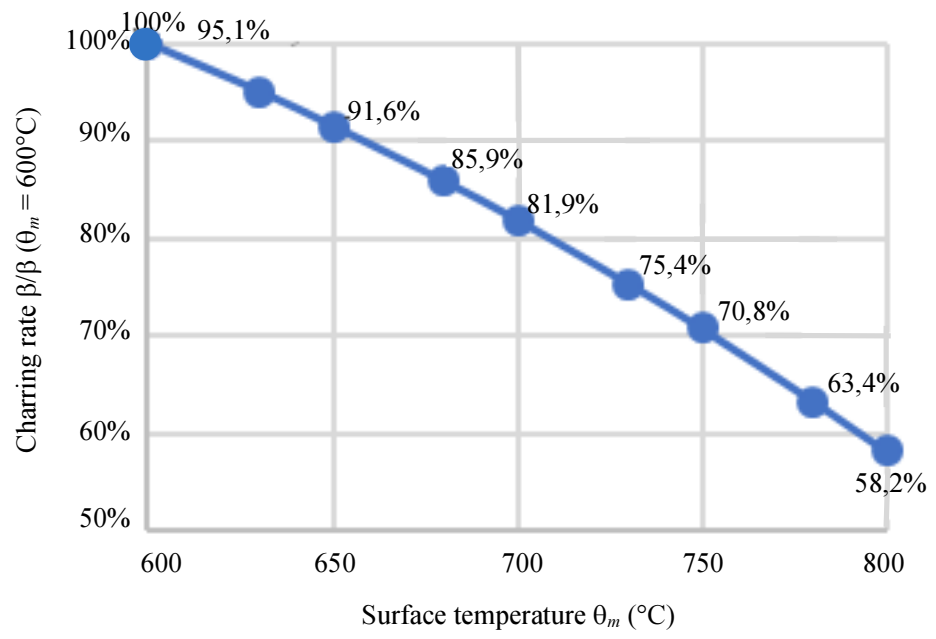

Fig. 5: The influence of the variable value of the surface temperature $\theta_{m}$ on the charring rate 


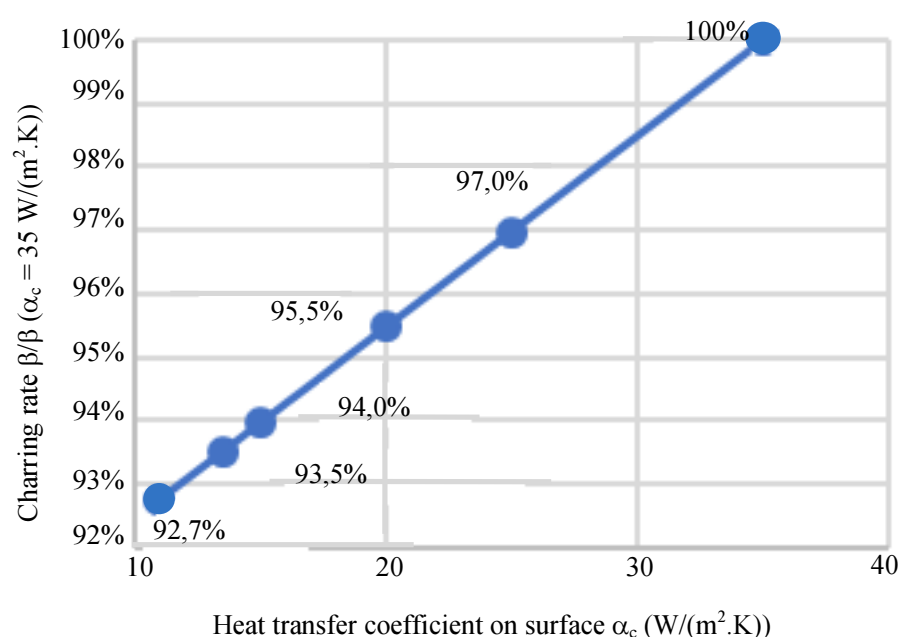

Fig. 6: The influence of the variable value of the heat transfer coefficient on the surface $\alpha_{c}$ on the charring rate

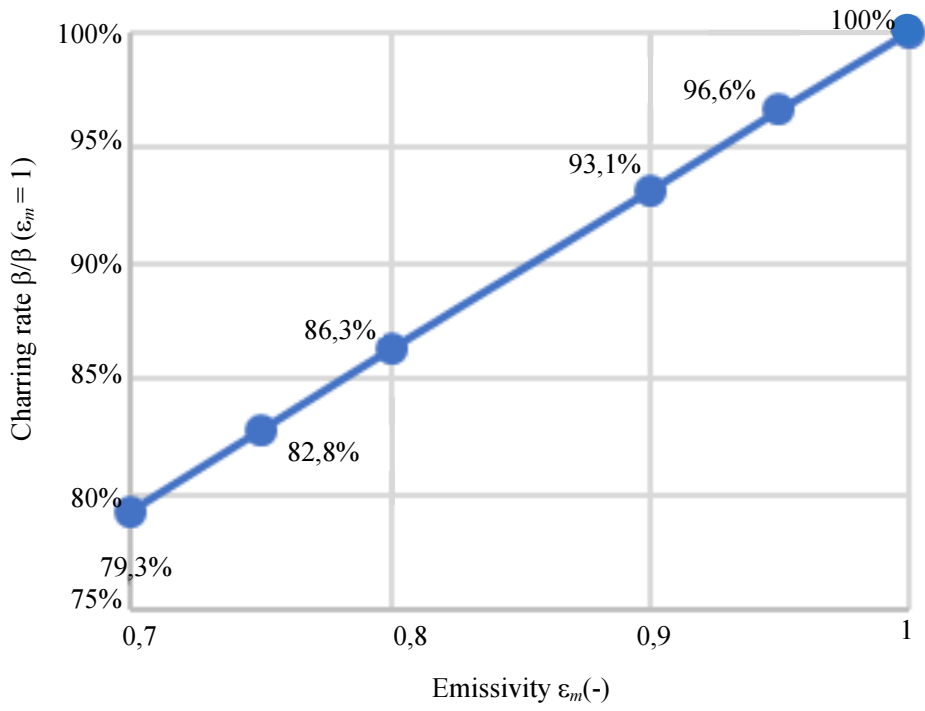

Fig. 7: The influence of the variable value of the surface emissivity of the member $\varepsilon_{m}$ (right) on the charring rate

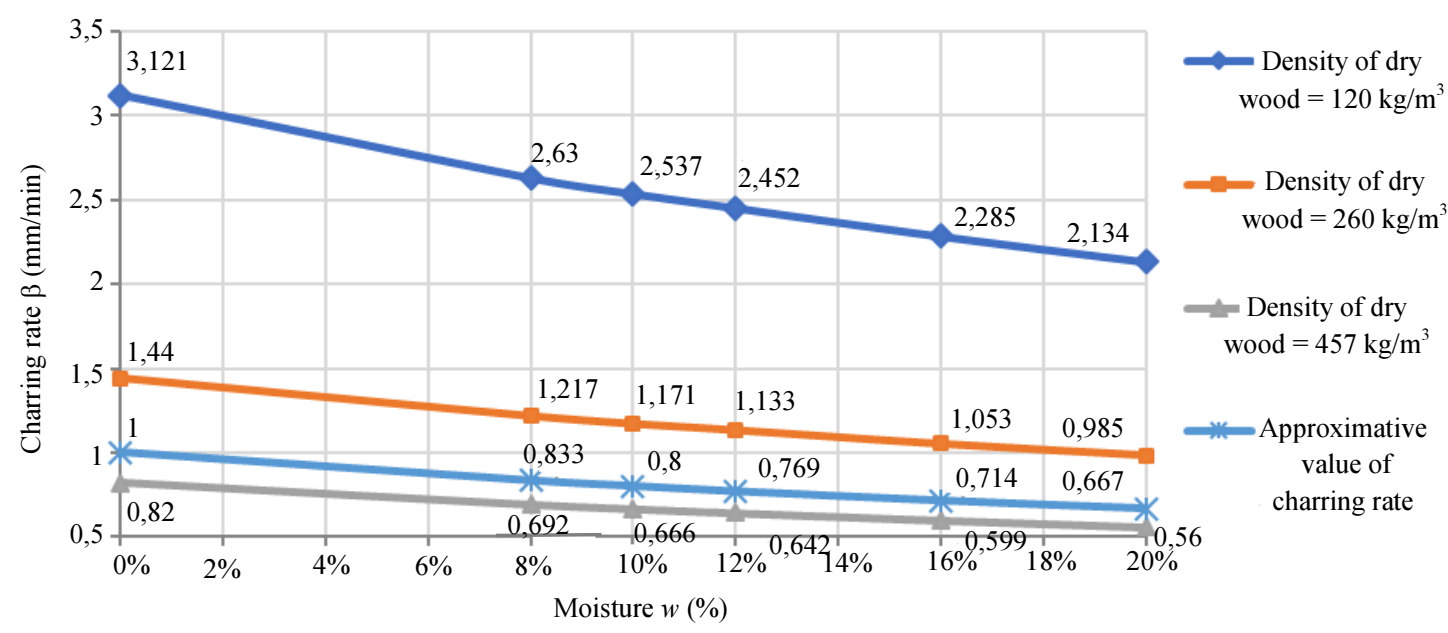

Fig. 8: The influence of the variable value of the density of dry wood $\rho 0$ and the wood moisture $w$ on the charring rate 


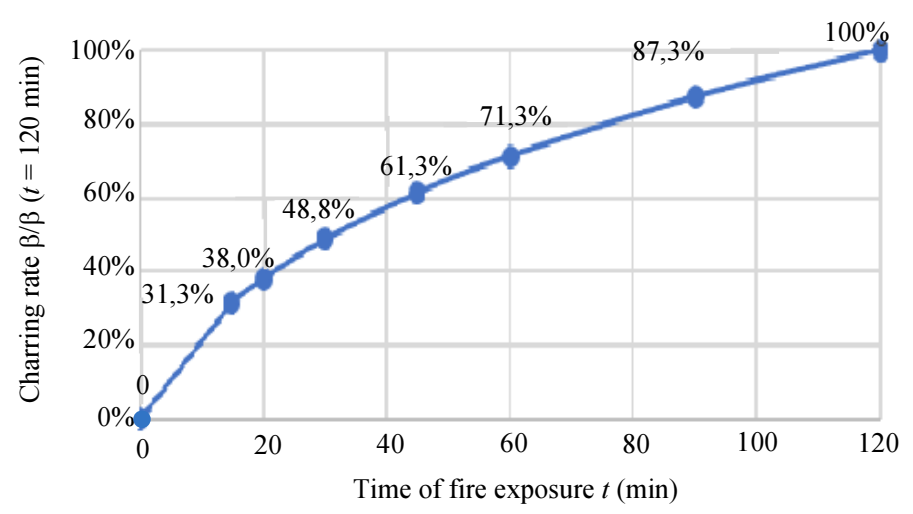

Fig. 9: The influence of the variable value of the time of fire exposure $t$ on the charring rate

The approximate equation (Fig. 8) for calculating the charring rate depending on the moisture content according to (Mikkola, 1991) is considered as follows:

$\beta=1 /(1+2.5 w)$

Where:

$w=$ The wood moisture content

Charring Rate Calculation According to (Hietaniemi, 2005)

The following equation was created to calculate the charring rate depending on the time of fire exposure according to (Hietaniemi, 2005):

$$
\beta=\frac{f\left(\chi_{\mathrm{O} 2}, t\right) \cdot\left(C \cdot q_{s t d}(t)^{p}\right)}{\left(\rho+\rho_{0}\right) \cdot(A+B \cdot w)} \exp \left(-\frac{t}{\tau}\right)
$$

Where:

$f\left(\chi_{O 2}, t\right)=$ The factor depending on the oxygen concentration (-)

$C=$ The parameter obtained from the constant heat flux (used value $3.93 \mathrm{~kW} / \mathrm{m}^{2}$ )

$q_{\text {std }}(t)=$ The heat flux $\left(\mathrm{kW} / \mathrm{m}^{2}\right.$

$p \quad=$ The parameter (used value 0.5 )

$\rho \quad=$ The wood density (used value $512 \mathrm{~kg} / \mathrm{m}^{3}$ )

$\rho_{0} \quad=$ The density of dry wood (used value 457 $\mathrm{kg} / \mathrm{m}^{3}$ )

$A=$ The parameter (used value $800 \mathrm{~kJ} / \mathrm{kg}$ )

$B=$ The parameter (used value $2490 \mathrm{~kJ} / \mathrm{kg}$ )

$w \quad=$ The wood moisture content (used value $12 \%$ )

$t \quad=$ The time of fire exposure (min)

$\tau=$ The time constant (used value $100 \mathrm{~min}$ )

The used input parameters in this analysis are stated in brackets and in the Table 1.

The following time-dependent components are calculated as:

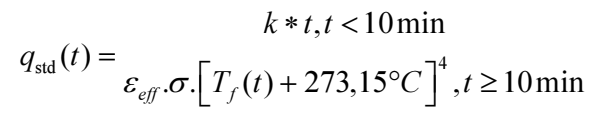

Where:

$\mathrm{k}=$ The parameter; min. $3.1 \mathrm{~kW} /\left(\min . \mathrm{m}^{2}\right)$, max. 4.0 $\mathrm{kW} /\left(\min . \mathrm{m}^{2}\right)$ (used value $3.55 \mathrm{~kW} /\left(\min . \mathrm{m}^{2}\right)$ )

$\varepsilon_{\text {eff }}=$ The effective emissivity; min. 0.7, max. 0.9 (used value 0.8 )

$\sigma=$ The Stefan-Boltzman constant $\left(5.67 \times 10^{-8}\right.$ $\left.\mathrm{W} /\left(\mathrm{m}^{2} \cdot \mathrm{K}^{4}\right)\right)$

$T_{f}(t)=$ The gas temperature according to the standard fire curve ISO 834 (it is referred to as $\left.\theta_{g}\right)\left({ }^{\circ} \mathrm{C}\right.$ )

$\mathrm{T}_{\mathrm{f}}(t)=T_{0}+345^{\circ} C \cdot \log (8 \cdot t+1)$

Where:

$T_{0}=$ The initial gas temperature (used value $20^{\circ} \mathrm{C}$ )

$\chi_{\mathrm{O} 2, \mathrm{t}}(t)=\Delta \chi+(21 \%-\Delta \chi) \cdot \exp \left(-\frac{t}{\tau_{O 2}}\right), t<20 \mathrm{~min}$

$$
\Delta \chi, t \geq 20 \mathrm{~min}
$$

Where:

$\chi_{O 2}(t)=$ The oxygen content depending on the time (\%)

$\Delta \chi=$ The parameter; average value $5.5 \%$ with deviation $4.1 \%$ (used value $5.5 \%$ )

$\tau_{\mathrm{O} 2}=$ The time constant (used value $4 \mathrm{~min}$ )

$\mathrm{f}\left(\chi_{\mathrm{O} 2, \mathrm{t}}\right)=\xi+(1-\xi) \cdot\left(\frac{\chi_{\mathrm{O} 2}(\mathrm{t})}{\chi_{\mathrm{O} 2}}\right)^{0,737}$

Where:

$\zeta=$ The parameter; min. 0.5, max. 0.65 (used value $0.575)$

$\chi_{O 2}=$ The normal volumetric oxygen concentration (used value 21\%)

The time dependent part of the wood charring rate is calculated as:

$\mathrm{f}\left(\chi_{\mathrm{O} 2, \mathrm{t}}\right) \cdot \mathrm{q}_{\mathrm{std}}(\mathrm{t})^{\mathrm{p}} \cdot \exp \left(-\frac{\mathrm{t}}{\tau}\right)$ 
Where:

$\mathrm{p} \quad=$ The parameter (used value 0.5 )

$\tau=$ The time constant (used value $100 \mathrm{~min}$ )

$f\left(\chi_{O 2}, t\right)=$ The factor depending on the oxygen concentration (-)

$q_{\text {std }}(t)=$ The heat flux $\left(\mathrm{kW} / \mathrm{m}^{2}\right)$

$t \quad=$ The time of fire exposure $(\mathrm{min})$

\section{Results}

The resulting values of the charring rate at the time of fire exposure (Fig. 10) were obtained from the abovementioned calculation methods and experiment. The inclination of the charring rate curve in the first five minutes is comparable for every method, later the course of this curve differs significantly. The charring rate should increase only until a specific time (according to (Erchinger, 2009)) and then start to decrease, followed by the formation of pyrolysis layer which acts as a thermal insulation. The charring rates according to the experiment, model from the software Ansys Workbench and the calculation according to (Hietaniemi, 2005) correspond with the experiment in the 10 th $\mathrm{min}$, the numerical model in the 20th $\mathrm{min}$ and the calculation according to (Hietaniemi, 2005) in the 30th min.

The calculation according to (Hietaniemi, 2005) is affected mainly by the heat flux and the oxygen concentration which change in the first 10 to $20 \mathrm{~min}$. This calculation shows the most rapid increase in the charring rate in the initial minutes, but reaches lower values compared to the other methods after the 90th minute.

The calculation according to (Mikkola, 1991) fails to consider the formation of the char layer in time, because it is significantly influenced by the increasing gas temperature during fire (it has parallels with the standard time-temperature curve). Therefore, this method is not suitable for the calculation of the charring rate in any time of the standard fire exposure. It is usable approximately between 45th and 90th $\mathrm{min}$. This is caused by the fact that the experiments made by (Mikkola, 1991) were performed in a cone calorimeter with an irradiance of $50 \mathrm{~kW} / \mathrm{m}^{2}$ which is constant in time. The standard time-temperature curve reaches lower temperatures in the first minutes. Therefore, the calculation according to (Mikkola, 1991) is only applicable for higher thermal load. Even though it is influenced by a variety of parameters, none of these reflect the changing temperature of the air. Such parameters should be implemented into the analytical calculations, since they determine its applicability in the first minutes of fire according to the standard time-temperature curve. However, according to e.g. (Tsantaridis and Östman, 1998; Babrauskas, 2005; Silcock and Shields, 2001; Xu et al., 2015), correlation between the tests in the cone calorimeter and those in a furnace with the standard fire curve can be established by means of an equation stated in (Tsantaridis and Östman, 1998).

It was not possible to obtain experimental results for longer duration of fire due to the failure of the beam in the 22 nd minute. However, this experiment was used as a representation of an actual case of the timber-concrete composite beam with real values of moisture and density which were used as input data for other analyses, for instance in the calculation model of the timber-concrete composite beam. It was not possible to use solely this model for the purpose of comparison with other methods due to dimensions of the timber cross-section.

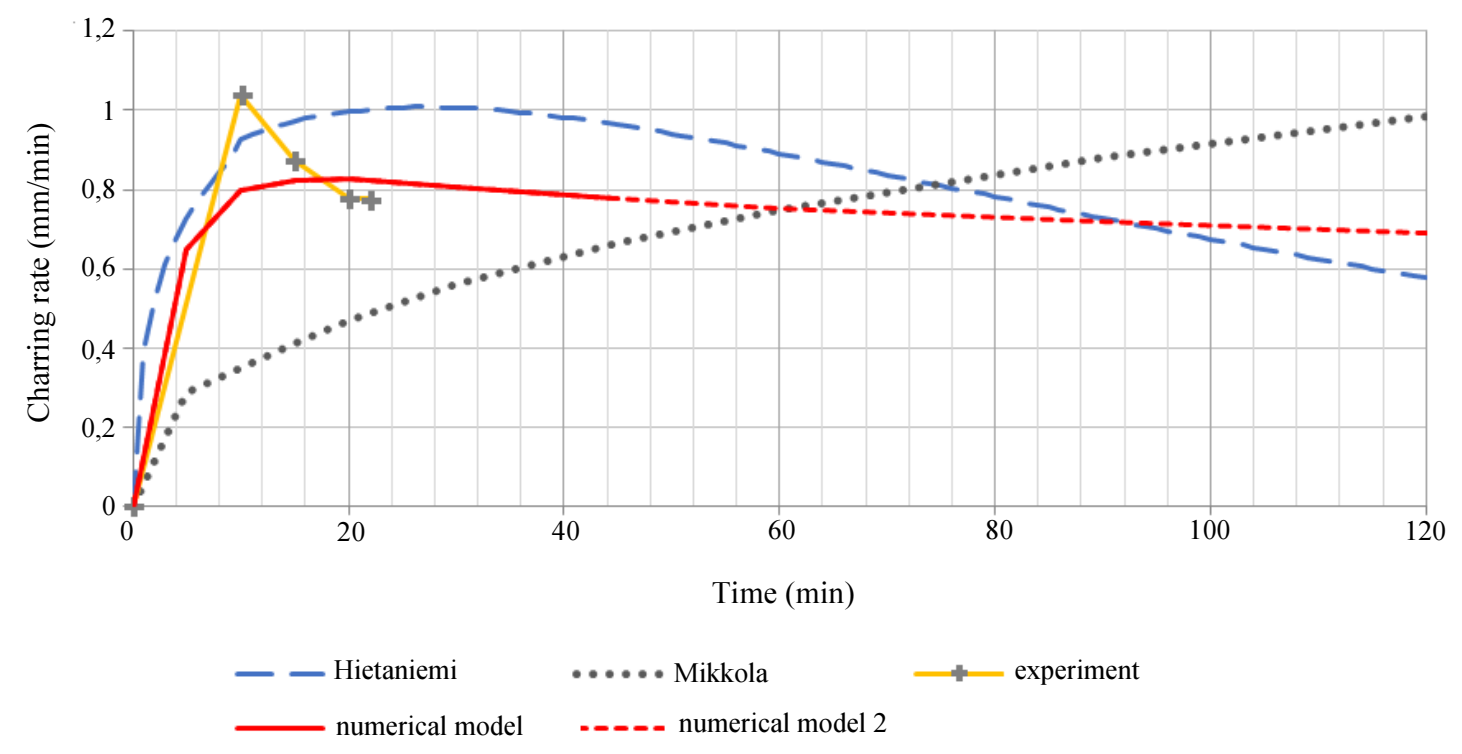

Fig. 10: Charring rates depending on the time of fire exposure according to various calculation methods 
Therefore, the second model of the timber cross-section was created with the same thermal properties, the same values of the thermal load (only this time applied on one side) and with bigger dimensions $(140 \times 160 \mathrm{~mm})$ to monitor the charring rate until the 120th minute. The charring rate was identical in both models in the first 45 min, but then it became influenced by the temperature from the bottom of the beam, in addition to the considerable influence of the corner rounding and the temperatures reached values which imply the destruction of the char layer. The charring rate in the second model (numerical model 2) continuously decreased until the 120th minute. It represents theoretical extrapolation of the first numerical model without influence of the corner rounding.

\section{Discussion and Conclusion}

It is possible to use various calculation methods to determine the charring rate and subsequently the residual cross-section. The results of the numerical analysis indicate that until the 20th minute, the charring rate can be considered as increasing, whilst after this time it starts to decrease. The charring rate according to the simplified calculation procedures is determined as a constant value during the whole time of fire exposure and, consequently, the use of this method is relatively fast and easy, even though it has certain limitations. These simplified methods are usable only for timber with $12 \%$ moisture, considering the normalised fire scenario with the ISO 834 curve and only certain fire protection materials can be used to represent protected surfaces. The advanced calculations, on the other hand, are less limited and can provide solutions to many cases of a real timber structure, provided that correct parameters and physical laws are chosen. Therefore, it is possible to solve, for example, the issues of Cross-Laminated Timber (CLT) members, various connections, various moisture, various fire scenarios, fissures, or other wood defects. The disadvantages of the advanced calculations are the demands on the computing program and the uncertain input parameters, since various authors present different attitudes to this issue. It is usually possible to change only thermal properties, such as the specific heat capacity, the thermal conductivity, the density depending on the temperature, or the surface emissivity in the numerical methods, but other parameters (the heat of vaporisation of dry wood, the surface temperature, the moisture etc.) which can decisively influence the charring rate can only be determined by the analytical calculations. For the analytical methods, it is advisable to use time dependent parameters which correctly represent the course of the charring rate as increasing in the initial minutes and decreasing afterwards. The experimental measurements also have certain advantages as well as disadvantages. They can be used to simulate any case in the structure with various thermal conditions, but the results can be influenced by several factors (for example the measurement of temperatures can be influenced by heat transfer by the thermocouple, by the distance between the thermocouple and timber etc.). The simplified methods according to (STN EN 1995-1-2, 2008) are the best methods to use in civil practice in common cases. It is suitable to use e.g. modelling in a FEM-based program for other (above mentioned) cases, since these allow incorporating the influence of moisture through modifications of thermal properties. In case of analytical methods, it is necessary to implement timedependent parameters.

Summary of this manuscript:

- The charring rate has the tendency to increase until a certain time and decrease afterwards, which corresponds with the experiment, numerical model and calculation according to (Hietaniemi, 2005).

- The calculation of the charring rate according to (Mikkola, 1991) is suitable only for high temperatures of constant values, otherwise it is necessary to implement time-dependent parameters for the calculation in the initial minutes of the standard fire curve.

\section{Acknowledgment}

The authors would like to acknowledge the support of Ing. Michal Botló, PhD. who provided language help.

\section{Funding Information}

The work presented in this paper is supported by the project of Grant Agency Czech Republic Coupled model of structural standard fire test, GACR 16-18448S.

\section{Author's Contributions}

All authors contributed equally to the work presented in this paper.

\section{Ethics}

The authors declare there is not any conflict of interest.

\section{References}

Babrauskas, V., 2005. Charring rate of wood as a tool for fire investigations. Fire Safety J., 40: 528-554.

DOI: 10.1016/j.firesaf.2005.05.006 
Beilicke, G., 2009. Holz Brandschutz Handbuch, 3rd Edn., Berlin: Ernst \& Sohn.

Cachim, P.B. and J.M. Franssen, 2010. Assessment of Eurocode 5 Charring Rate Calculation Methods. Fire Technology, 46: 169-181. DOI: $10.1007 / \mathrm{s} 10694-009-0092-\mathrm{x}$

Caldová, E., L. Blesák, F. Wald, M. Kloiber and S. Urushadze et al., 2014. Behaviour of timber and steel fibre reinforced concrete composite constructions with screwed connections. Wood Res., 59: 639-660.

de Souza Costa, F. and D. Sandberg, 2004. Mathematical model of a smoldering log. Combustion Flame, 139: 227-238. DOI: 10.1016/j.combustttame.2004.07.009

Erchinger, C.D., 2009. Zum Verhalten von mehrschnittigen Stahl-Holz-Stabdübelverbindungen im Brandfall, Zürich, PhD. Thesis, Institut für Baustatik und Konstruktion Eidgenössische Technische Hochschule Zürich.

Frangi, A., 2010. Fire safety in timber buildings: Technical guideline for Europe.

Hietaniemi, J. and E. Mikkola, 2010. Design fires for fire safety engineering, Espoo: VTT Technical Research Centre of Finland.

Hietaniemi, J., 2005. A probabilistic approach to wood charring rate. Finland: VTT Information Service.

Klippel, M., 2014. Fire safety of bonded structural timber elements. Zurich, PhD. Thesis. Institut für Baustatik und Konstruktion Eidgenössische Technische Hochschule Zürich,

Kollmann, F., 1951. Technologie des Holzes und der Holzwerkstoffe, Springer Verlag, Berlin, Germany.

König, J., 2005. Structural fire design according to Eurocode 5-design rules and their background. Fire Materials, 29: 147-163. DOI: 10.1002/fam.873

Mikkola, E., 1989. Puupinnan syttyminen (ignition of wooden surface), Espoo: VTT Tiedotteita.

Mikkola, E., 1990. Charring of wood, Espoo: VTT Tutkimuksia 689, ISBN-10: 951-38- 3711-4, pp: 40.
Mikkola, E., 1991. Charring of Wood Based Materials, Fire Safety Science.

Schmid, J., M. Klippel, A. Just and A. Frangi, 2014 Review and analysis of fire resistance tests of timber members in bending, tension and compression with respect to the Reduced Cross-Section Method. Fire Safety J. 68: 81-99.

DOI: 10.1016/j.firesaf.2014.05.006

Silcock, G.W.H. and T.J. Shields, 2001. Relating char depth to fire severity conditions. Fire Mater.

STN EN 13183-1, 2003. Moisture content of a piece of sawn timber - Part 1: Determination by oven dry method Thermal Analysis Guide, 2009. Canonsburg: ANSYS.

STN EN 1363-1, 2013. Fire resistance tests. Part 1: General Requirements.

STN EN 1991-1-2, 2007. Eurocode 1: Actions on structures - Part 1-2: General actions - Actions on structures exposed to fire.

STN EN 1992-1-2, 2007. Eurocode 2: Design of concrete structures - Part 1-2: General rules Structural fire design.

STN EN 1995-1-2, 2008. Eurocode 5: Design of timber structures - Part 1-2: General - Structural fire design.

Tinney, E.R., 1965. The combustion of wooden dowels in heated air. Proceedings of the 10th Symposium (International) on Combustion, the Combustion Institute, Pittsburg, PA, pp: 925-930.

Tsantaridis, L.D. and B.A.L. Östman, 1998. Charring of protected wood studs. Fire and Materials: Fire Mater.

Werther, N., 2016. External and internal factors influencing the charring of timber - an experimental study with respect to natural fires and moisture conditions: Structures in fire. Lancaster: DEStech Publications.

Xu, Q., L. Chen, K.A. Harries, F. Zhang and Q. Liu et al., 2015. Combustion and charring properties of five common constructional wood species from cone calorimeter tests. Construction Building Materials, 96: 416-427.

DOI: $10.1016 /$ j.conbuildmat.2015.08.062 